\title{
The Characteristics of Early Helladic II Period Wood Recovered From An Underwater Shipwreck Site Near Dokos, Greece
}

\author{
M.W. Pendleton, ${ }^{*}$ T.C. Stephens, ${ }^{*}$ A. Ellis* and G. Fox** \\ *Microscopy and Imaging Center, Texas A\&M University, College Station, TX 77845 \\ **Department of Anthropology, California State University, Chico, CA 959290400
}

Wood samples taken from an underwater shipwreck site dating to the Early Helladic II period, (approximately 2200 B.C.) near Dokos, Greece in 1991 were examined utilizing specifc techniques to better reveal the fine structural details of wood fragments using light [1], transmission [2], and scanning electron microscopy [3]. Specific characteristics [4] observed using these techniques were entered into the General Unknown Entry and Search System for computer-aided wood identification to facilitate the identification of these wood fragments [5]. The characteristics of one of the hardwood fragments examined include vessel elements with simple perforation plates and numerous intervascular pits, as shown in Fig. 1. This underwater shipwreck site was discovered by Peter Throckmorton in 1975 in 15 to 25 m of water, close to the promontory of Myti Kommeni in the small northern bay of Skindos. In 1989 the Dokos Project, directed by Yamis Vichos of the Hellenic Institute for Marine Archaeology, began the underwater investigation of the wreck site which yielded the wood samples in this study. Because of local site disturbances and seismic activity, this study was initiated to determine whether or not the wood fragments recovered at the site were associated with the structure or contents of the wreck.

\section{References}

[1] A.C. Barefoot and F.W. Hankins, Identification of Modern and Tertiary Woods, Clarendon Press, Oxford, 1982.

[2] K. Messner, Trans. Br. Mycol. Soc. 83 (1984) 209.

[3] C.J. Biermann et al., J. Agric. Food Chem., 35 (1987) 713.

[4] E.A. Wheeler, Int. Assoc. Wood Anat. Bull. 10 (1989) 221.

[5] R.B. Miller et al., Creation of a Large Database with IAWA Standard List Characters, Forest Products Laboratory, Madison, 1988. 


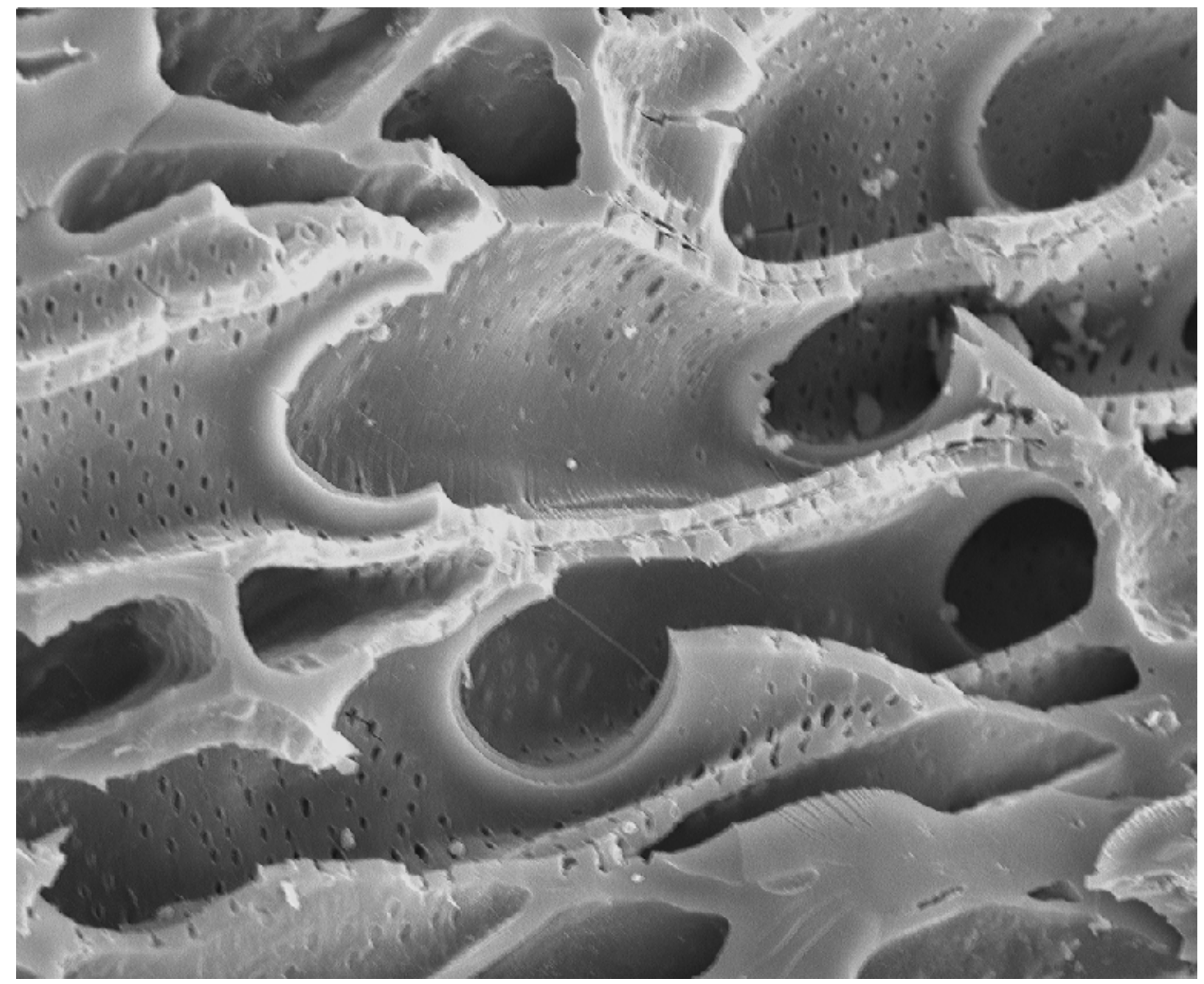

FIG. 1. Simple perforation plates and numerous intervascular pits (plate diameter is approximately 20 micrometers). 